\title{
Voltage stability improvement of distributed generation
}

\author{
${ }^{1}$ Sweta, ${ }^{2}$ Mohamad Samir \\ ${ }^{I}$ Electrical Engineering Department,DIT University, India \\ ${ }^{2}$ Electrical Engineering Departments, DIT University, India
}

\begin{abstract}
This Paper presents an analysis of voltage stability in distribution systems, in the presence of distributed generation (DG). This paper include Steady state voltage and current and load Flow steady for reduce loss in power distribution system. In this paper included result of Matlab model and MIPower Experiments for voltage stability improvement of Distributed Generation. IN this paper mainly the focus is to minimize the power losses so that the voltage stability of distributed generation improved as a result.
\end{abstract}

Keywords: Distributed Generation, Radial Distribution Network, Voltage Stability,Dynamic stability, Electromagnetic Transient, Relay Coordination, Reliability, and Transient Stability etc.

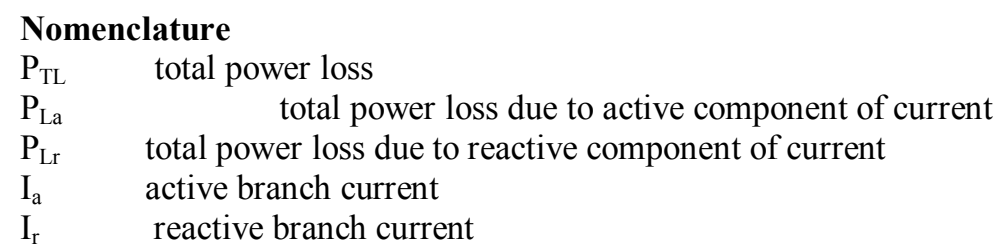

$\begin{array}{ll}\text { Abbreviations } & \\ \text { AND } & \text { active distribution network } \\ \text { DG } & \text { distributed generator } \\ \text { RDN } & \text { radial distribution network } \\ \text { T\&D } & \text { transmission and distribution } \\ \text { VSI } & \text { voltage stability index } \\ \text { PLI } & \text { power loss index } \\ \text { DGSI } & \text { distributed generator suitability index } \\ \Delta & \text { small change in variable } \\ \text { Subscript } & \\ \text { I } & \text { node }\end{array}$

\section{Introduction}

These Paper present Voltage stability improvements in Distributed Generation using different-different type methodology .In this paper we analysis MAT LAB Simulink Model for DistributedGeneration system. In this model we used four load(4 load), and 21 buses ,DG source. In this model we arranged the loads connecting with buses which occurs low power losses .we used here three source(A,B,C).

In this paper also included analysis of Power Distributed generation using MI Power experiments .Here we used different -different type method for analysis for power losses in Distributed Generation System .Dynamic stability method we used 4 number of generators ,4 number of voltage regulators , 3 number of governors for analysis. Electromagnetic Transient method we analysis load flow by Gauss-Siedel Method. Relay Coordination method we used Over Current Relay Co-ordination for analysis DG.Reliability in this method we analysis output for DG. Transient Stability we analysis load flow by Newton Rapshon Method. 


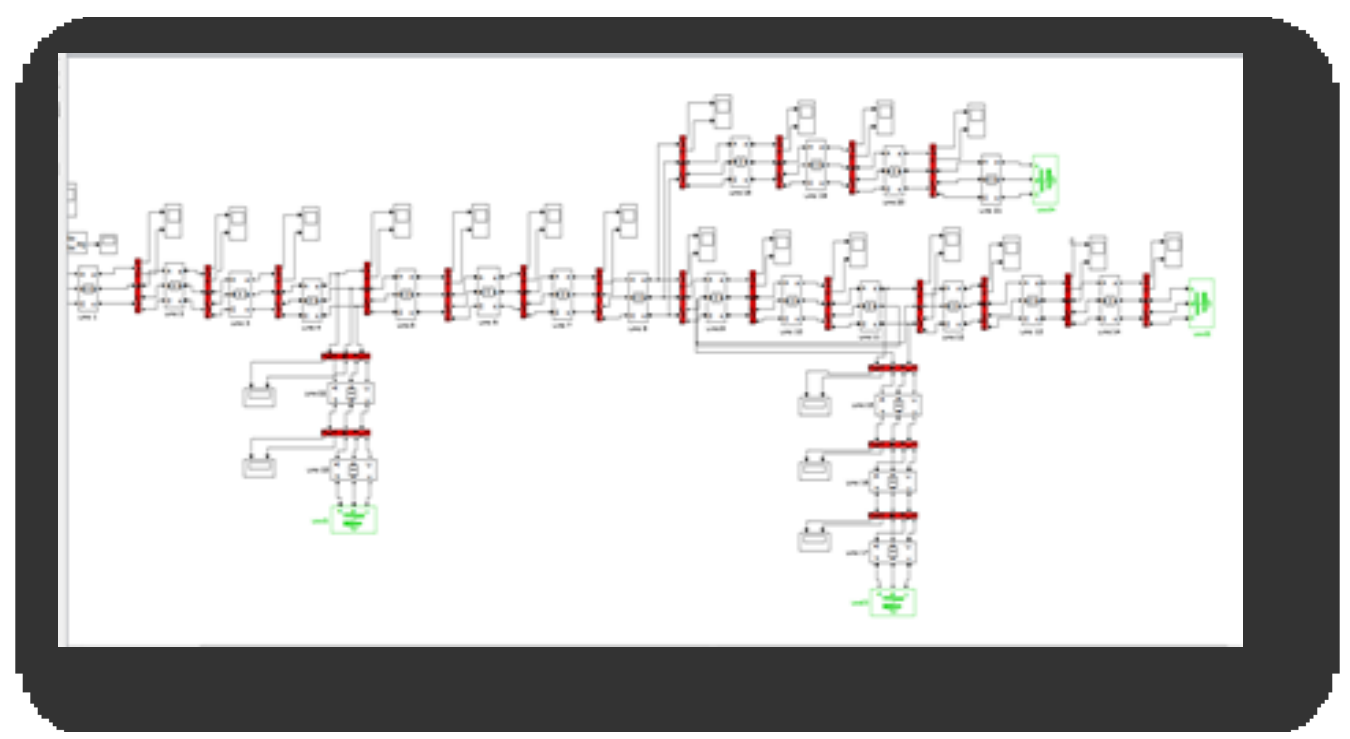

\section{Load Flow Study}

A power flow study (load-flow study) is a steady-state analysis whose target is to determine the voltages, currents, and real and reactive power flows in a system under a given load conditions. Basically Newton-Raphson and Gauss-Seidel methods are used for load flow study but now it become incompetent due to such factors radial structure, high ratio of resistance and reactance and unbalanced loads and many other factors.

\section{Methodology}

The total power loss in a distribution system having ' $n$ ' number of branches is given by

$\mathbf{P}_{\mathrm{TL}}=\sum_{\mathrm{I}=\mathbf{1}}^{\mathrm{n}} \mathbf{I}_{\mathbf{i}}{ }^{2} \mathbf{R}_{\mathbf{i}}$

$\mathrm{I}_{\mathrm{i}}$ is the current magnitude and $\mathrm{R}_{\mathrm{i}}$ is the resistance. $\mathrm{I}_{\mathrm{i}}$ Can beobtained from load flow study. Thebranch current has twocomponents, active component Ia and reactive component Ir .

The total losses associated with these two components can bewritten as

$\mathbf{P}_{\mathrm{TL}}=\mathbf{P}_{\mathrm{La}}+\mathbf{P}_{\mathrm{Lr}}$

$\mathbf{P}_{\mathrm{TL}}=\sum_{\mathrm{i}=\mathbf{1}}^{\mathrm{n}} \mathbf{I}_{\mathrm{ai}}{ }^{2} \mathbf{R}_{\mathbf{i}}+\sum_{\mathrm{i}=\mathbf{1}}^{\mathrm{n}} \mathbf{I}_{\mathrm{ri}}{ }^{2} \mathbf{R}_{\mathbf{i}}(\mathbf{2 3})(3)$

\subsection{Dynamic stability}

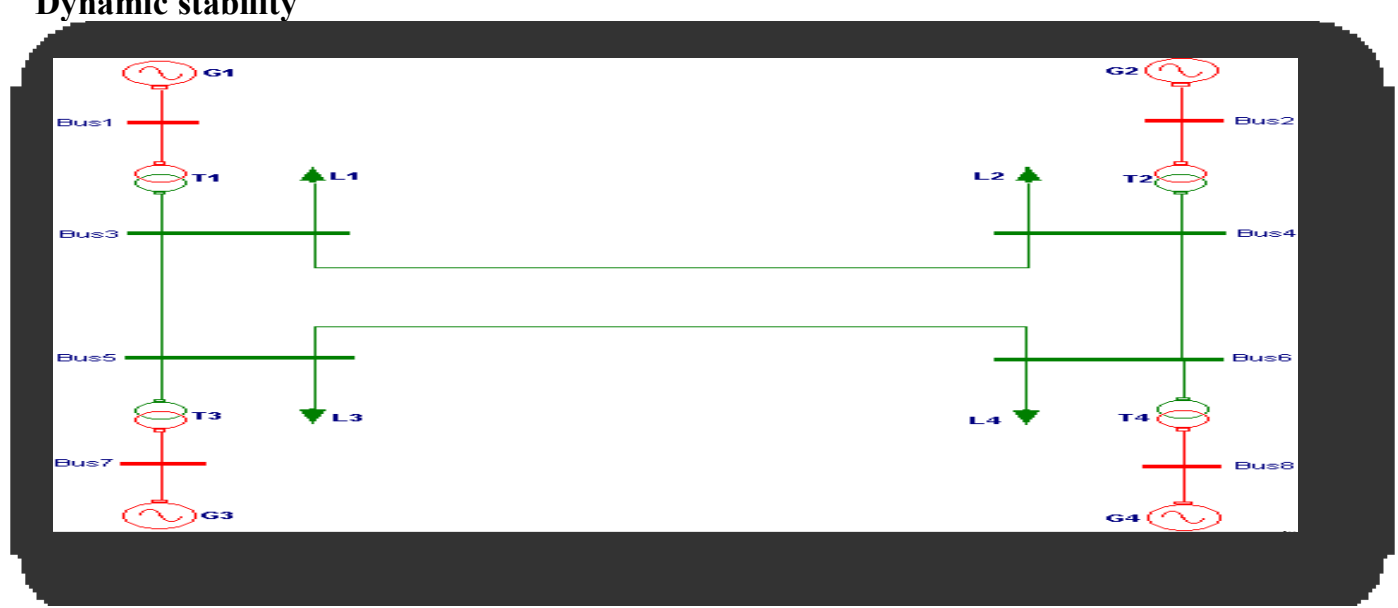

DYNAMIC STABILITY STUDIES

SCHEDULE NO: 0 CONTINGENCY NO: 0 CONTINGENCY NAME: Base Case

\footnotetext{
Total number of generators $\quad: \quad 4$

Total number of voltage regulators $: 4$

Total number of governors : 3
} 
Total number of static var compensators: 0

Swing bus considered for the study : 1

Data output option

Number of variables for plot $\quad:-1$

Plot interval (multiple of time step) : 10

Base MVA : 100.000

Nominal System Frequency: $50.000 \mathrm{~Hz}$

Total study time : 5.000 seconds

Time step for the study: 0.005 seconds

Machine number where disturbance is considered: 2

Change in generator reference angle $\quad: 0.00000$

Change in generator reference voltage $: 0.50000$

Change in generator reference power $: 0.00000$

Change in svc reference

: 0.00000

2

$$
00000
$$

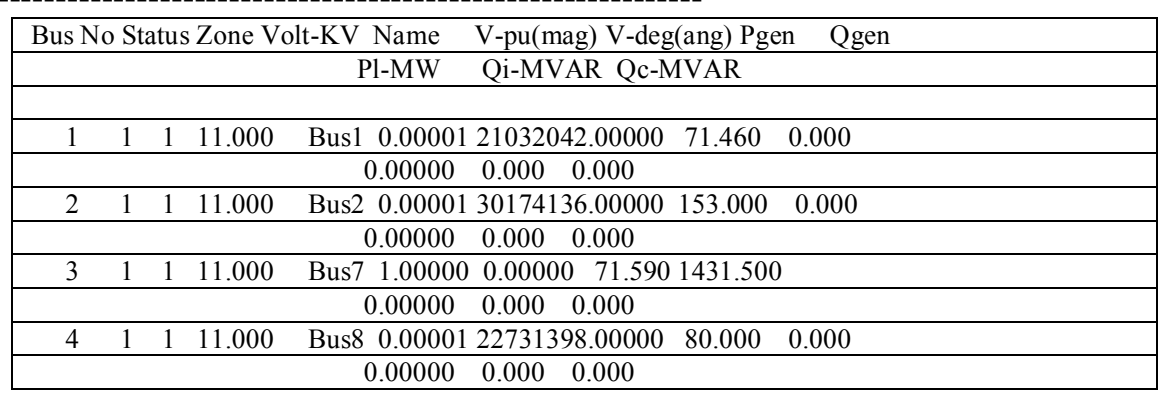

\subsection{Electromagnetic Transient:}

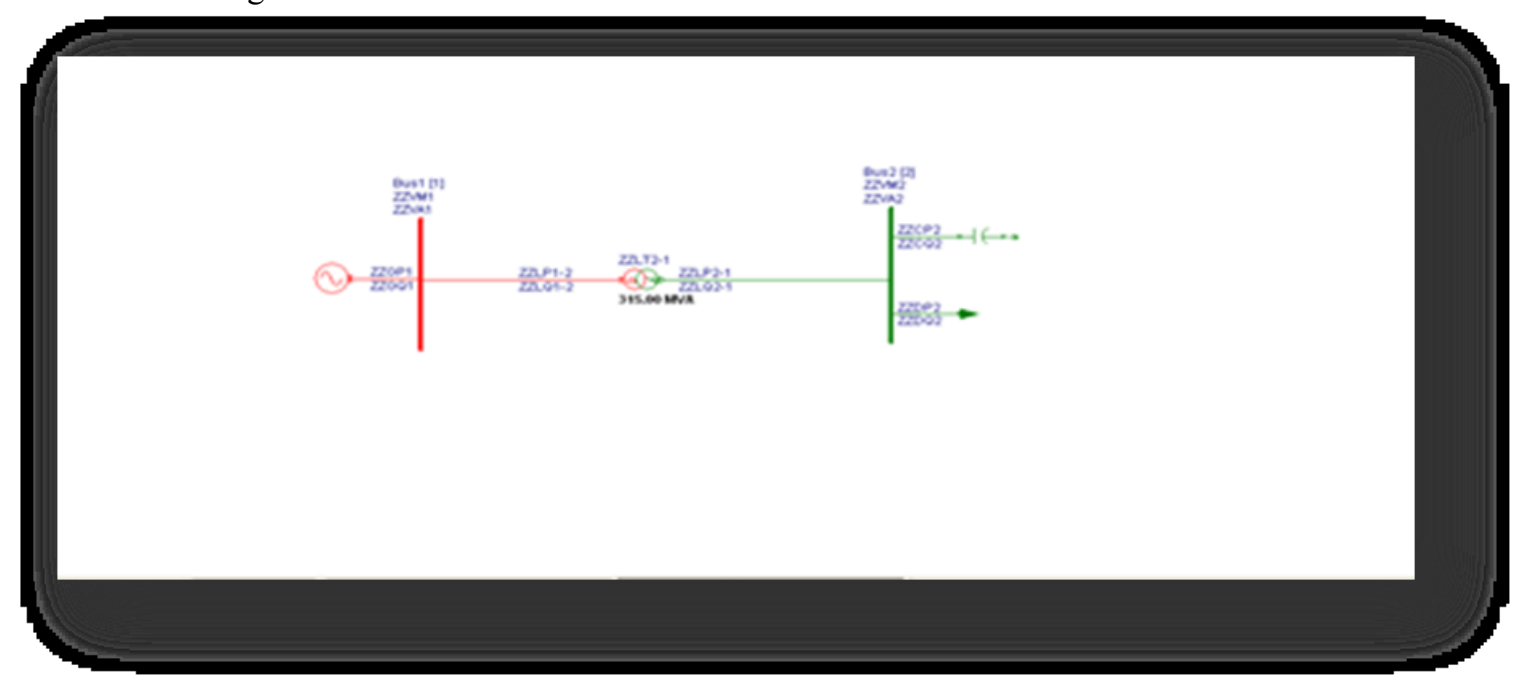

LOAD FLOW BY GAUSS-SIEDEL METHOD

CASE NO: 1 CONTINGENCY:0 SCHEDULENO: 0

CONTINGENCY NAME: Base Case RATING CONSIDERED: NOMINAL

LARGEST BUS NUMBER USED : : 2 ACTUAL NUMBER OF BUSES $\quad$ : 2

NUMBER OF 2 WIND TRANSFORMERS: 1 NUMBER OF 3 WINDTRANSFORMERS: 0

NUMBER OF TRANSMISSION LINES : 0

NUMBER OF SERIES REACTORS $\quad: \quad 0 \quad$ NUMBER OF SERIES CAPACITORS $\quad: \quad 0$

NUMBER OF CIRCUIT BREAKERS : 0

NUMBER OF SHUNT REACTORS $\quad: \quad 0 \quad$ NUMBER OF SHUNT CAPACITORS $\quad: \quad 1$

NUMBER OF SHUNT IMPEDANCES : 0

NUMBER OF GENERATORS $\quad: \quad 1$ NUMBER OF LOADS $\quad: 1$

NUMBER OF LOAD CHARACTERISTICS: 0 NUMBER OF UNDER FREQUENCY RELAY: 0 
NUMBER OF GEN CAPABILITY CURVES: 0 NUMBER OF FILTERS $\quad$ : 0 NUMBER OF TIE LINE SCHEDULES : 0

NUMBER OF CONVERTORS $\quad: \quad 0 \quad$ NUMBER OF DC LINKS $\quad: \quad 0$

NUMBER OF SHUNT CONNECTED FACTS: 0

POWER FORCED LINES : 0

NUMBER OF TCSC CONNECTED : 0

NUMBER OF SPS CONNECTED $\quad: 0$

NUMBER OF UPFC CONNECTED : 0

3.3:Transient Stability

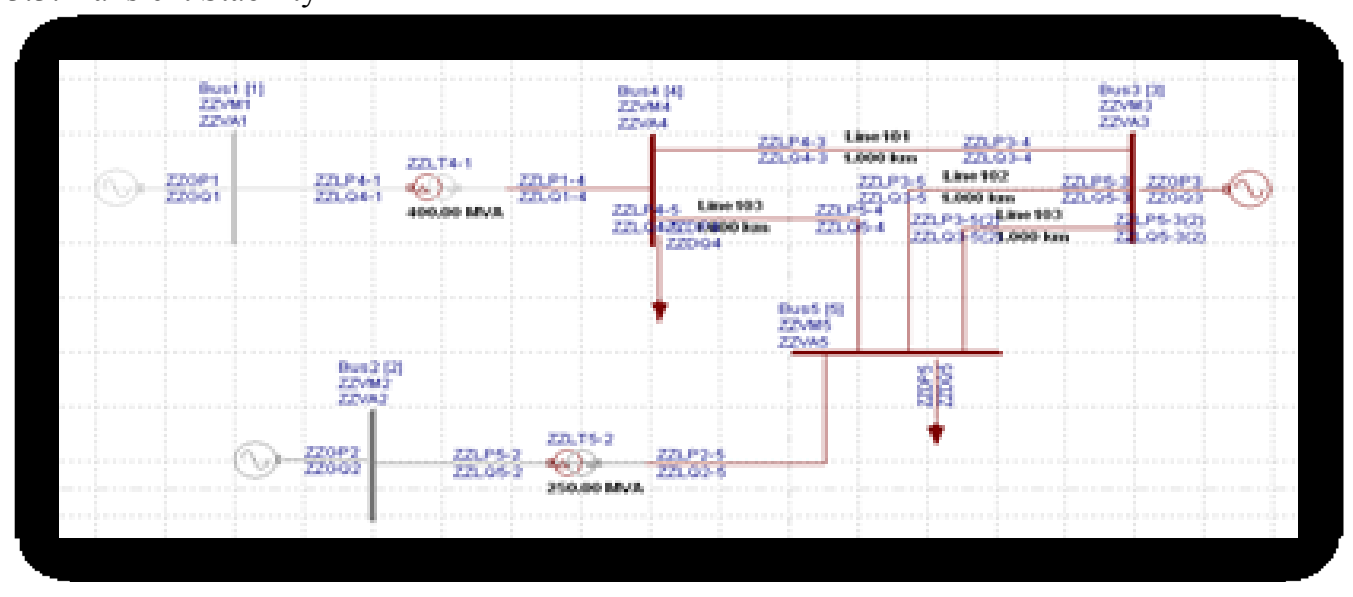

LOAD FLOW BY NEWTON RAPHSON METHOD

CASE NO: 1 CONTINGENCY:0 SCHEDULENO: 0

CONTINGENCY NAME: Base Case RATING CONSIDERED: NOMINAL

VERSION NUMBER: 7.3

$\% \%$ First Power System Network

LARGEST BUS NUMBER USED $\quad: 5$ ACTUAL NUMBERS OF BUSES $\quad: 5$

NUMBER OF 2 WIND. TRANSFORMERS:2 NUMBERS OF 3 WINDS. TRANSFORMERS: 0

NUMBER OF TRANSMISSION LINES : 3

NUMBER OF SERIES REACTORS $\quad: \quad 0$ NUMBER OF SERIES CAPACITORS $: 0$

NUMBER OF CIRCUIT BREAKERS : 0

NUMBER OF SHUNT REACTORS $\quad: \quad 0$ NUMBER OF SHUNT CAPACITORS $\quad: 0$

NUMBER OF SHUNT IMPEDANCES : 0

NUMBER OF GENERATORS : 3 NUMBER OF LOADS $: 2$

NUMBER OF LOAD CHARACTERISTICS: 0 NUMBER OF UNDER FREQUENCY RELAY: 0

NUMBER OF GEN CAPABILITY CURVES: 0 NUMBER OF FILTERS $\quad: 0$

NUMBER OF TIE LINE SCHEDULES : 0

NUMBER OF CONVERTORS $\quad: \quad 0 \quad$ NUMBER OF DC LINKS $\quad: \quad 0$

NUMBER OF SHUNT CONNECTED FACTS: 0

POWER FORCED LINES $\quad: 0$

NUMBER OF TCSC CONNECTED : 0

NUMBER OF SPS CONNECTED $: 0$

NUMBER OF UPFC CONNECTED $: 0$

SOURCES:

\section{Results}

1: 'U_A: Main Source' $=8385.42 \mathrm{~V} 0.00^{\circ}$

2: 'U_B: Main Source' $=8385.42 \mathrm{~V}-120.00^{\circ}$

3: 'U_C: Main Source' $=8385.42$ V $120.00^{\circ}$

MEATSUREMENTS:

1: 'U A: V-I Measurement9 ' $=521.80 \mathrm{~V}-70.50^{\circ}$ 
2: 'U B: V-I Measurement9 ' $=521.80 \mathrm{~V} 169.50^{\circ}$

3: 'U C: V-I Measurement9 ' $=521.80 \mathrm{~V} 49.50^{\circ}$

4: 'U A: V-I Measurement8 ' $=685.20 \mathrm{~V}-67.88^{\circ}$
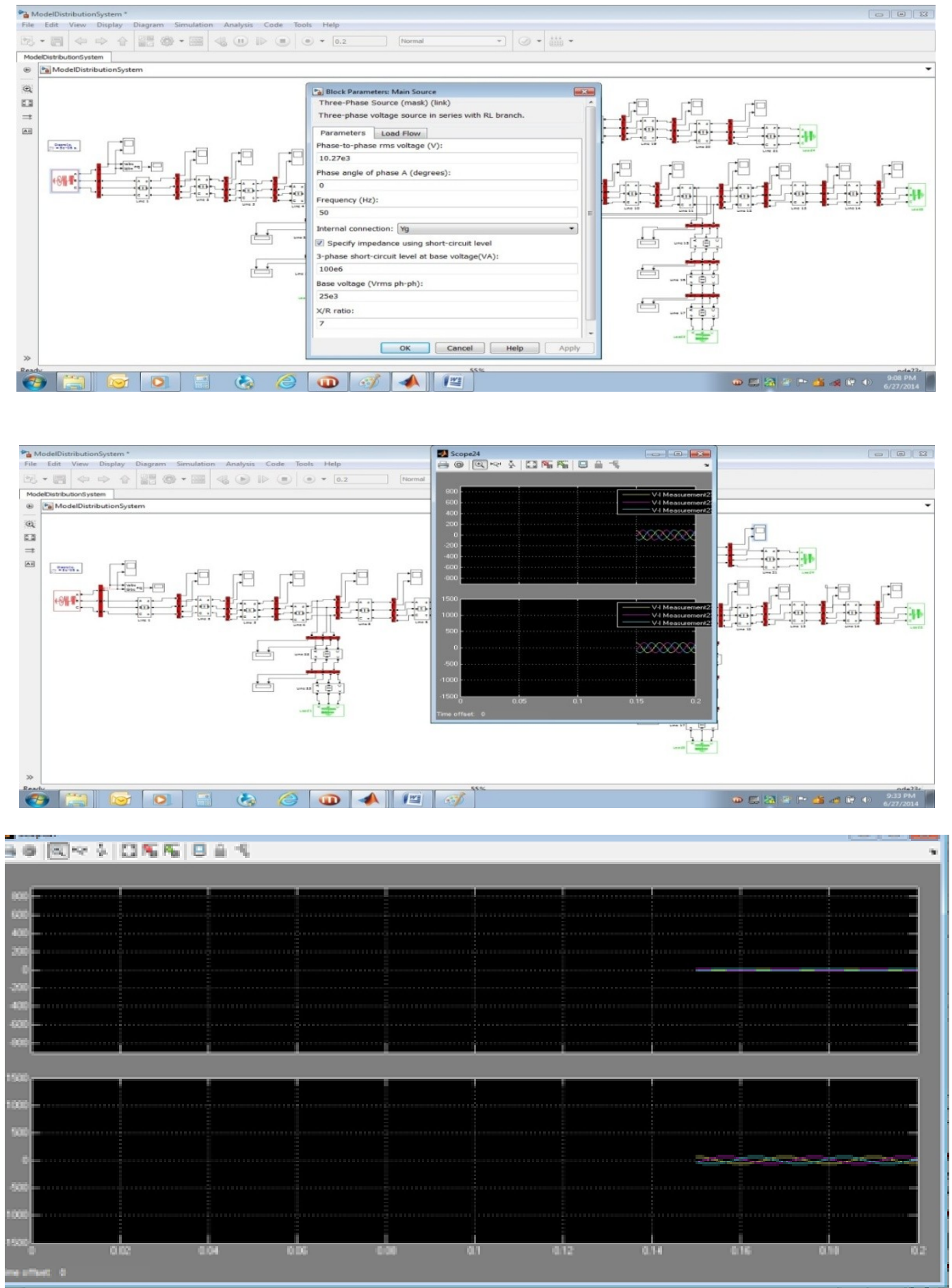

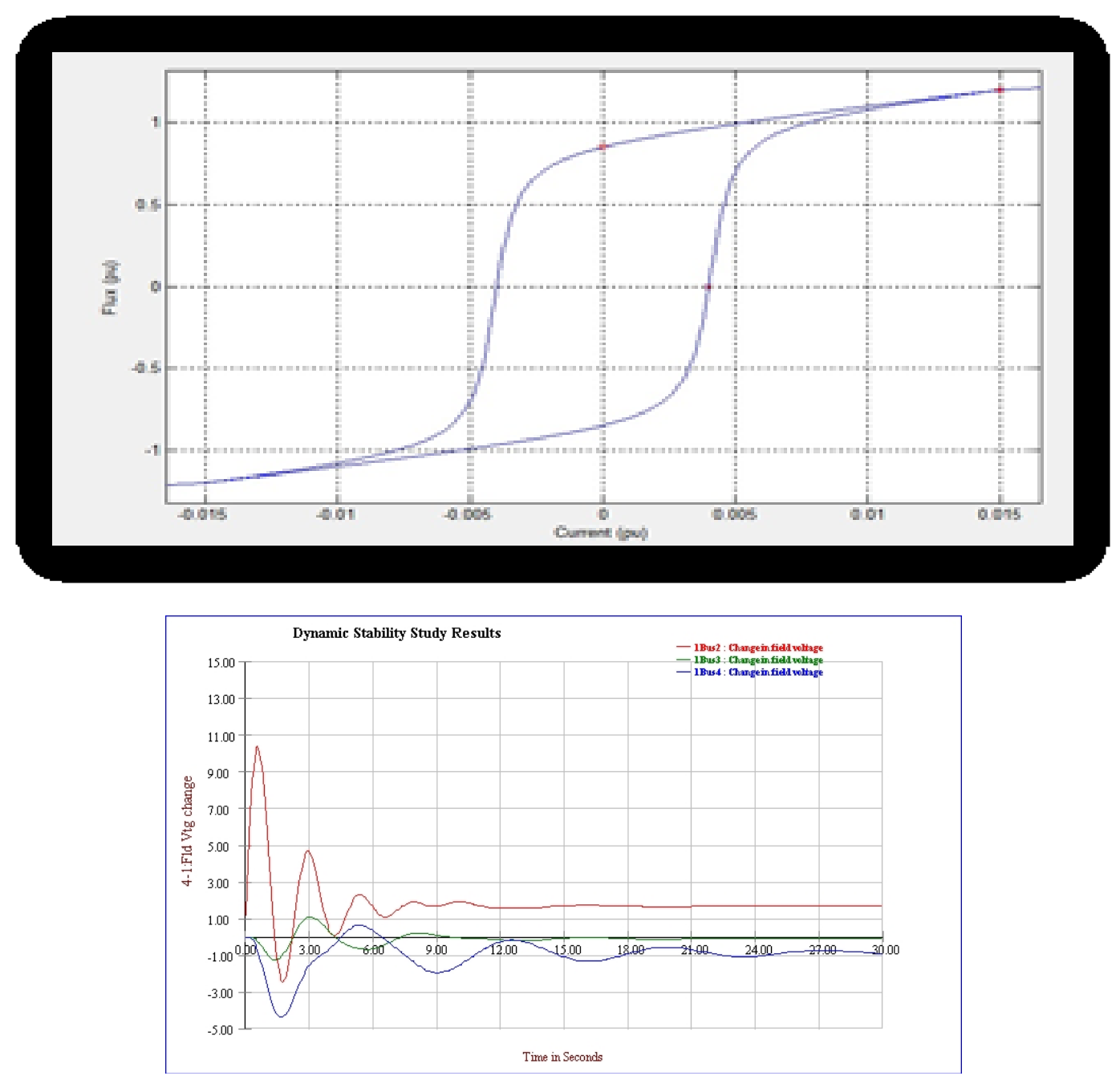

\section{Conclusion:}

Sizing and Placement of DG make important role in Power Distributions Networks. This Paper we used different -different method of reduced Powerloss. We donethis type of Sizing and placement of which is stabilized Voltage. We done this simulation for Geranial type of Power distributions networks .Relays, Junction Box and Type of Load also effects power output .According to Power distribution Network power loses are increased. In futures we can done more reduction in Power losses by improving method of sizing, placing and quality of junction box. Also make it cost effective.

\section{Refrences}

[1]. Chowdhury S, Chowdhury SP, Crossley P.2009. Micro grids and Active Distribution Networks. 1st ed. London. IET Renewable Energy Series

[2]. Willis H. L, 2000. Analytical methods and rules of thumb for modeling DG distribution interaction. IEEE Proc. PES summer meeting, vol.3, pp. 1643-.

[3]. Wang C, and Nehrir MH. 2004. Analytical approach for optimal placement of distributed generation sources in Power systems. IEEE Trans. PWRS.

[4]. Griffin T, Tomosovic K, Secrest D, and Law A. 2000 Placement of Dispersed Generation systems for reduced Losses. In proceedings of 33rd Annual Hawaii International conference on systems sciences, Maui, Hawaii.

[5]. Mardanesh M, and Gharehpattan GB. 2004. Siting and sizing of DG units using GA and OPF based technique. IEEE Region 10 Conference.

[6]. Tripathy SC, Prasad GD, Malik OP, and Hope GS. 1982. Load flow solutions for Ill-conditioned power systems by a Newton-like method, IEEE Trans Power Ap Syst PAS-101 pp.3648-3657, D.O.I: 10.1049/ip-c: 19800043.

[7]. Tinney WG and Hart CE. 1967. Power flow solutions by Newton's method. IEEE Trans Power Ap Syst PAS.

[8]. Zhang F and Cheng CS. 1997.A modified Newton method for radial distribution system power flow analysis. IEEE Trans Power System.

[9]. Teng JH. 2002. A modified Gauss-Seidel algorithm of three-phase power flow analysis in distribution networks. Electric Power and Energy Systems.

[10]. Shirmohammadi D, Hong HW, Semlyen A and Luo GX. 1988. A compensation-based power flow method for weakly meshed distribution and transmission. 
[11]. Thukaram D, Banda HMW and Jerome J. 1999. A Robust three-phase power flow algorithm for radial distribution systems. Electric Power System Research 50, 227-236.

[12]. Ranjan R, Venkatesh B, Chaturvedi A and Das D. 2004. Power flow solution of three-phase unbalanced radial distribution network. Electric Power Component Systems.

[13]. Y. M. Atwa, E. F. El-Saadany, M. M. A. Salama, and R. Seethapathy, "Optimal renewable resources mix for distribution system energy loss minimization," IEEE Trans. Power Syst., vol. 25, no. 1, pp. 360-370, Feb. 2010.

[14]. Y. M. Atwa and E. F. El-Saadany, "Optimal allocation of ESS in distribution systems with a high penetration of wind energy," IEEE Trans.Power Syst., vol. 25, no. 4, pp. 1815-1822, Nov. 2010.

[15]. L. L. Grigsby, The Electric Power Engineering Handbook. New York: CRC/IEEE, 2001.

[16]. R. B. Prada and L. J. Souza, "Voltage stability and thermal limit: Constraints on the maximum loading of electrical energy distribution feeders," Proc. Inst. Electr. Eng.-Gen., Transm. Distrib., vol. 145, pp. 573-577, 1998.

[17]. C. Haiyan and C. Jinfu, "Power flow study and voltage stability analysis for distribution systems with distributed generation," in Proc.IEEE PES General Meeting, 2006, 8 pp.

[18]. W. Freitas, L. C. P. DaSilva, and A. Morelato, "Small-disturbance voltage stability of distribution systems with induction generators,’IEEE Trans. Power Syst., vol. 20, no. 3, pp. 1653-1654, Aug. 2005.

[19]. W. Freitas, J. C. M. Vieira, L. C. P. da Suva, C. M. Affonso, and A.Morelato, "Long-term voltage stability of distribution systems with induction generators," in Proc. IEEE PES General Meeting, 2005, vol. 3, pp. 2910-2913.

[20]. N. Jenkins, R. Allan, P. Crossley, D. Kirschen, and A. G. Strb, Embedded Generation. : IET, 2000.

[21]. W. Freitas, A. Morelato, X. Wilsun, and F. Sato, "Impacts of AC generators and DSTATCOM devices on the dynamic performance of distribution systems," IEEE Trans. Power Del., vol. 20, pp. 1493-1501, 2005.

[22]. J. G. Slootweg and W. L. Kling, "Impacts of distributed generation on power system transient stability," in Proc. IEEE PES SummerMeeting, 2002, vol. 2, pp. 862-867.

[23]. S. Kumar Injeti and Dr. Navuri P Kumar'Optimal Planning of Distributed Generation for Improved Voltage Stability and Loss Reduction" in International Journal of Computer Applications (0975 - 8887) Volume 15- No.1, February 2011 